\title{
Identifying and Meeting the Counselling Needs of Distance Learners as Shapers of Students' Academic Success: The Case of University of Cape Coast, Ghana
}

\author{
Lydia Aframea Dankyi \\ College of Distance Education, University of Cape Coast, Cape Coast, Ghana \\ Email: lydia.dankyi@ucc.edu.gh
}

How to cite this paper: Dankyi, L.A. (2019) Identifying and Meeting the Counselling Needs of Distance Learners as Shapers of Students' Academic Success: The Case of University of Cape Coast, Ghana. Open Journal of Social Sciences, 7, 12-25. https://doi.org/10.4236/jss.2019.712002

Received: October 19, 2019

Accepted: November 30, 2019

Published: December 3, 2019

Copyright $\odot 2019$ by author(s) and Scientific Research Publishing Inc. This work is licensed under the Creative Commons Attribution International License (CC BY 4.0).

http://creativecommons.org/licenses/by/4.0/ (c) (i) Open Access

\begin{abstract}
The purpose of the study was to identify and meet the counselling needs of distance students, focusing on College of Distance Education (CoDE), University of Cape Coast (UCC) diploma students, in order to help shape students' academic success. The moderating roles of organisational culture and effective counselling service delivery were also considered. The descriptive survey design was used. The sample size of the study was 1110. Purposive sampling technique was used to select three regional capitals (Greater-Accra, Ashanti and Northern Regions) while stratified random sampling technique was used to select the respondents. Questionnaire with a reliability coefficient of 0.895 was the instrument used. Out of the 1110 questionnaires administered, the researcher was able to collect 1075 completed and accurate questionnaires, representing 96.8 percent response rate. The independent samples t-test and hierarchical linear multiple regression analysis were used to analyse the data. The findings of the study revealed that diploma students of CoDE had four broad priority counselling needs. Furthermore, the counselling needs of distance students were not adequately met by the College. The study concludes that whenever the organisational culture of the college supports the activities of the counselling unit, and also when the service delivery of the unit is perceived to be effective, the unit is able to meet students' identified priority needs which will in turn lead to students' academic success. However, to enhance academic success, students' personal characteristics such as gender, age and level of study should be considered when identifying and meeting the counselling needs of students. It is recommended to the College to nurture the kind of atmosphere that will support counselling activities in order to help boost students' academic success.
\end{abstract}




\section{Keywords}

Academic Success, Distance Student, Counselling Needs, Counselling Service Delivery, Organisational Culture

\section{Introduction}

Globally, the adjustment difficulties of distance learners have been an emerging issue, especially their ability to adapt to the existing university structures that were designed for regular students. Unlike regular students, distance students are usually older, have jobs, family responsibilities and mostly might have been away from their books for a longer period which make adjustment very difficult [1]. Many studies have proved that the adjustment difficulties like appetite disturbance, concentration problems, stress and depression are most evident in fresh distance learners [2]. This shows that, in spite of the higher preference for distance education, distance students in Ghana are still facing challenges including methods of learning, adjustment and management of time [3]. Other characteristics of distance learners such as social and financial responsibilities take much of their time which would have been spent on their studies [4].

To help distance students in resolving their adjustment issues and challenges, many universities have made efforts in the form of establishing counselling unit. The purpose was to support services to provide intervention to the students so that their socio-psychological problems will not interfere with their academic performance and success, and to also bridge the gap of transactional distance [5]. However, the identification of students' counselling needs by school counsellors is crucial in the provision of relevant counselling services to students in schools. Similarly, the organisational culture of the college is vital in supporting the activities of counselling. Generally students' counselling needs are in four broad categories namely personal/social, career/vocational, educational/academic and practical needs [6].

The College of Distance Education (CoDE), University of Cape Coast (UCC) is perceived to be the leading institution in the delivery of distance education in Ghana. To achieve its core mandate, the University offers a number of support services to staff and students. One of such is counselling services. Counselling services are important in the life of every student, especially in the life of the distance students since it helps in boosting their adjustment in the distant environment and academic success meaningfully. However, if the organisational culture of the University does not support the counselling activities of the institution, it may thwart the positive impact of counselling services with regard to the identification and meeting of students' counselling needs.

The College of Distance Education (CoDE, UCC) established a counselling since 2011 to help its distance students to remove barriers that prevent them from achieving academic success and address their social, educational, and ca- 
reer problems [7]. However, to provide relevant services, students' needs must be identified [8]. This can only be done through a technique called needs assessment. The study, therefore, assessed the counselling needs of diploma students of CoDE with a view to making counselling relevant and effective.

\subsection{Statement of the Problem}

Distance education has long been associated with unsatisfied academic performance [1]. This problem has been the biggest drawback facing this form of education all over the world. Also, it has a negative impact on the student's self-esteem and self-confidence, and also on the part of the institution, it may be considered as a sign of inefficiency [9]. To help students deal with this problem and other adjustment difficulties, the CoDE has put in place a number of interventions. These interventions are the use of modules as study guides for every course mounted in the semester, the face-to-face instructional sessions where course tutors guide the students, provision of counselling services, and the one week session solely for revision before end of semester examinations. With all these interventions, one would expect that students will do well academically. However, academic performance of distance education students of CoDE, particularly diploma students, is unsatisfactory and also the graduation rate is not encouraging among students [7].

For instance, in the 2016/2017 academic year, statistics of diploma students of CoDE indicated that out of a total of 5263 students who graduated, as many as 4263 representing $80.99 \%$ percent had below barely satisfactory grade [CGPA < 2.50] (CoDE, 2017a). Also, at the end of the first semester examination of the 2017/18 academic year, over 4000 students had failed more than two courses [10]. These percentages are very alarming and a critical look at the rate indicates there is problem among students. One can, therefore, say that the majority of the students at the diploma level have problems in their academic activities as seen from the high percentage (80.99\%) of students obtaining below barely satisfactory grades. The questions, therefore, are: Why are distance students not doing well? Is their poor academic performance due to their inability to adjust to the system they are exposed to? Is it due to certain specific needs that the system is not meeting? Is it due to their time and work pressures? Most of these questions can be answered when the needs of students are assessed.

Awabil [6] stated that experts in the field of counselling strongly believe that needs assessment is a prerequisite for effective development and practice of counselling in both educational and non-educational settings. To be able to provide adequate support services in the form of counselling to distance students there is the need to know their varied needs and put them into consideration when planning counselling services for them. If students' needs are identified and catered for it will in turn help in finding out the extent to which the services provided meet the needs of students. However, these dynamics can be thwarted when the organisational culture of the college does not support counselling ac- 
tivities of the institution. It appears there has been no specific study that has looked at the counselling needs of distance students and also to find out if the existing counselling services are structured to meet the needs of students. This lacuna calls for the need to assess the counselling needs of distance students in CoDE, UCC.

\subsection{Purpose of the Study}

The purpose of the study was to identify and meet the counselling needs of distance students, focusing on CoDE, UCC diploma students, in order to help shape students' academic success. The moderating roles of organisational culture and effective counselling service delivery were also considered. Furthermore, the study examined the controlling role of gender, age and level of students on counselling needs of students.

\subsection{Significance of the Study}

First, the dissemination of research findings on the assessment of the counselling needs of distance students could lead to a wider adoption of appropriate counselling strategies and in the long run student learning would improve through effective counselling services. Also, it is hoped that the findings of the study will inform policy making, practice and research. The findings could guide management of CoDE to see the need to establish well-resourced counselling units in each region. It is also envisaged that training programmes on guidance and counselling would be instituted for course tutors. In practice, the findings may serve as the basis upon which effective and comprehensive counselling services could be designed. It would help counsellors in the various study centres to be more proactive and innovative to design very comprehensive educational programmes for students to enhance their learning adaptability to the system in order to yield better academic results. The findings may further broaden intellectual horizon of counsellors and thereby sharpening their skills to render more effective counselling services to meet the counselling needs of students. This, in a long run, would boost distance students' academic success.

\subsection{Delimitations}

The study focused on assessing counselling needs of CoDE, UCC diploma students at the regional study centres. The diploma students of CoDE were chosen as the main respondents because they are those in majority when it comes to issue of low and unsatisfactory academic performance. Diploma students' unsatisfactory academic performance could be attributed to lack of pre-admission counselling and the needed support to meet their needs during their programmes of study. The study again was delimited to four main components of counselling needs of students. These are educational/academic needs, career/vocational needs, personal/social needs, and practical problems. Other variables such as organisational culture, academic success, effective counselling service delivery, students' 
gender, age and level of programme were considered.

\subsection{Limitations of the Study}

The collection of the data for the study was through questionnaire which was mainly close ended items. This is likely to limited respondents in their responses on their needs. It is therefore recommended for other researchers to explore the needs of students quantitatively. This limitation notwithstanding, resultant findings of the study would constitute a strong basis for generalisation.

\section{Literature Review}

Counselling occupies a very strategic position in any educational system of which distance education is no exception. Counselling is a scientific process of assistance extended by an expert to a person who needs help [11]. It involves a relationship between two persons in which one of them (counsellor) attempts to assist the other (counselee) in organising himself/herself as to attain a particular form of happiness, adjusting to a life situation or in short self-actualisation [12]. It is one of the important factors in determining students' academic success. Therefore, students' academic success can be improved through effective counselling service delivery.

Students in distance learning systems face not only the problems of conventional students, but also those generated by the system itself. Mau [13] identified Chinese and American distance students' needs to be transportation, social, academic and financial. Other challenges face by distance learners include how to combine their work with their studies, manage family and social activities. According to Herr [14], they are often misunderstood, isolated and finally drop out from the programme they embark on. They also feel burdened with studies and do not know where to turn for help. This is the very reason why there is the need to identify these needs and cater for them. This will help distance learners to be successful in their academic endeavour.

Academic success in this context does not mean passing their various course of study with only good classes but also to acquire the necessary skills for life and the world of work [14]. The students need motivation to learn and excel. The preparations of brochures describing study techniques, the setting up of residential course centres, the dispatch of audio-visual aids and the provision of quiet study rooms in public buildings, can all keep the students overcome their difficulties and improve dialogue [8]. Effective counselling service for distance students is relevant to ensure that the needs of students are met. However, the culture of the college must support the counselling services given to students to help boost the impact of it to ensure meaningful increase in the success of students.

Empirically, Awabil [6] study revealed that in relation to practical needs, students are more worried about school fees, inadequate transport facilities, poor facilities for persons with disability, and inadequate medical facilities. On voca- 
tional/career needs, students needed information on how to prepare and attend job interviews, need for information about occupations or career and need to visit an industry. With respect to personal/social needs, self-understanding was the most significant because students wanted to know more about their interest and potentialities in order to make realistic career and educational decisions and choices. Their study also revealed that students' specific educational needs were difficulty in discussing problems with lecturers, difficulty coping with course work loads and difficulty coping with style of teaching in the polytechnic [6].

Another study by Okyere [15] also found out the specific needs of students under the four broad categories. The study revealed that specific practical needs that were of great concern to students were inadequate lecture room space and high user fee charged by the university. This need may not be different from that of distance students of Code. This because most of the study centres are SHS rented premises and so there is the likelihood that the lecture halls may be inadequate and uncomfortable with higher user fee as well. With regard to career needs students expressed interest on the need for more information on occupations or careers, need for information about how to prepare and attend interviews and the need to find placement for industrial attachment. The results of their study also showed that under the personal/social category, students greatly desired self-understanding, how to resolve interpersonal conflict. The study further revealed that student did not desire any specific educational needs [15].

\subsection{Conceptual Framework}

The argument of the study is supported by the Input-Environment-Output (IEO) model of Astin which asserts that for effective counselling service delivery, there is the need to identify the needs of students in order to meet them. This can be done by putting in appropriate interventions such as meaningful counselling services delivery. Astin's model postulates that student academic achievement is directly affected, or is a function of a student's involvement in college [16]. Therefore, it is appropriate to link intended student outcomes to the programme's ability to elicit sufficient student investment of effort and energy to achieve the desired result. This means, the input variables will affect the needs of students and the kind of culture and environment that will interact with both the input and needs will also determine the output, either positive or negative. However, these needs cannot be catered for when they are not known. This call for the need to assess the various counselling needs of students in order to develop, design and implement appropriate counselling intervention to support them in order for them to meet these counselling needs. The conceptual argument of the study is depicted in Figure 1.

The argument of the study is that, the identified priority needs of students, which are treated as input and independent variables, are the various needs of students. When these needs are met, it will lead to meaningful increase in students' academic success. However, the counselling needs of students can be influence by their gender, age, and level of programme. Also, the influence of the 


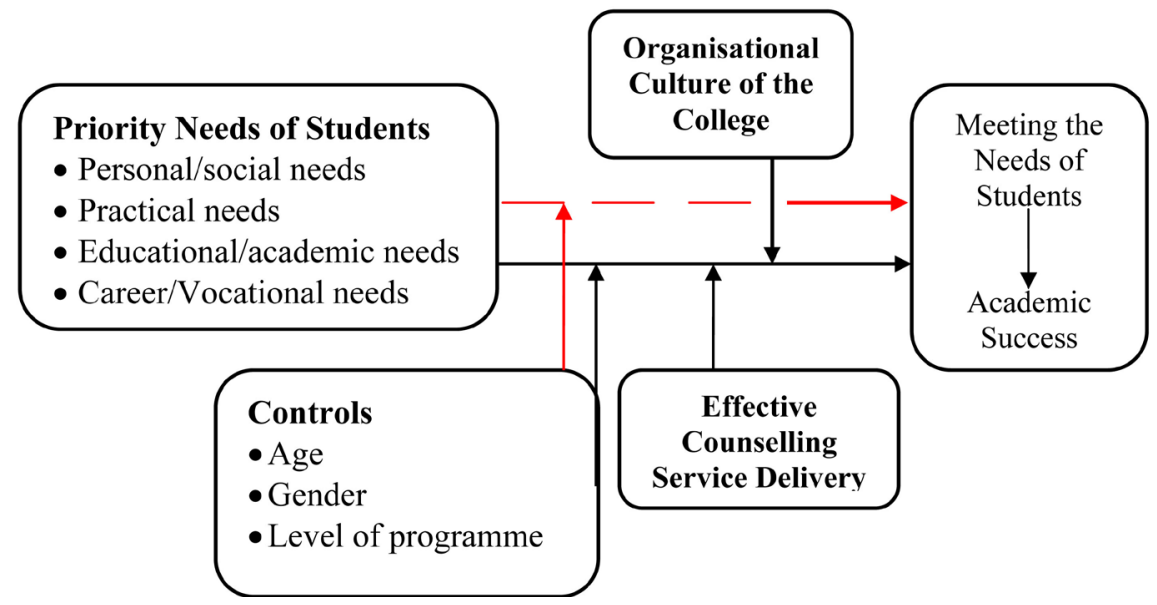

Figure 1. Conceptual framework of the study. Source: Author's construct (2019).

identified needs on students' academic success can be thwarted or boosted by the culture of the college and also by the effective nature of the counselling service delivered to students. It must be emphasised that, counselling services cannot meet the needs of students without the organisational culture support. When the culture of the college does not support counselling services, the effort will not yield good results. With the needed and supportive culture, the Counselling Unit of the College can meet the needs of students by identifying them, and providing effective counselling services. This in the long run will lead to meaningful increase in students' academic success.

\subsection{Research Methods}

This study adopted the quantitative approach. The descriptive survey design was employed. The target population for the study was all students of CoDE, UCC, as at the end of 2016/2017 academic year (48,622). However, the accessible population was all diploma students of CoDE, UCC as at the same academic year. The total population of diploma distance students of the College was 36,798 [17]. Kumar [18] recommended that in a descriptive study, it is appropriate to use a sample size of two to five percent of the study population. In line with the recommendation of Kumar [18], it was appropriate to use a sample size of 1110 . Using a recommended percentage of sample size by Kumar [18], the minimum required sample size generated was 1110 which represents 3.016 percent of the total population.

The purposive sampling technique was employed to pick one region from each of the three Zones. The regional capitals (Greater-Accra, Ashanti and Northern Regions) of each of the zones were purposively sampled because not all regions under the various zones offered all the diploma programmes. The stratified sampling procedure was used to select respondents from each of the study centres of the three regions selected based on gender and level of programme strata. Sampling frames were designed for each of the regions.

A Counselling needs assessment Questionnaire was the instrument used to 
collect the data. The questionnaire was adapted from Apreko [19] with a Cronbach's alpha reliability co-efficient of 0.895 which was deemed acceptable [20]. The questionnare was designed for students, and it was in four sections, namely: $\mathrm{A}, \mathrm{B}, \mathrm{C}$, and $\mathrm{D}$. The sections were on the following corresponding themes: background characteristics of respondents, counselling needs of students, providers of counselling services, and the extent to which counselling needs of students are met by the College, effective service delivery mechanism of the College and challenges militating against students in accessing counselling services.

Out of the 1110 questionnaires administered, the researcher was able to collect 1,075 completed and accurate questionnaires, representing 96.8 percent response rate. Inferential statistical tools such as independent samples t-test and hierarchical linear multiple regression analysis were used to analyse the data in order to deal with the purpose of the study. These statistical tools were used because all the pooled variables were measured numerically using unilinear scale data.

\section{Results of the Study}

Generally, to provide counselling services to students, there is the need to identify and know their priority needs in order to provide services that will meet these needs.

Based on the recommendation of Pallant [21], the study adopted mathematical approximation techniques to interpret the mean scores. Thus Strongly Agree (4.0 - 3.5), Agree (3.4 - 2.5), Disagree (2.4 - 1.5), and Strongly Disagree (1.4 1.0). The cut-off point for determining a priority need is a mean score of 2.5 . The 2.5 is an average score of the responses from the unilinear scale i.e. $(1+2+$ $3+4) \div 4)$.

The study first examined the most prevalent counselling needs of diploma students of CoDE, UCC with respect to the four broad categories of students' needs. The results are presented in Table 1.

The criterion for determining a priority need is a mean score of 2.5 or above. As depicted in Table 1, respondents indicated that they have various needs in the four broad categories. Specifically, respondents' indicated their needs for educational/academic issues $($ Mean $=2.773$, Std. Dev. $=0.37)$. In relation to career/vocational needs, respondents again indicated their needs $($ Mean $=2.772$, Std. Dev. $=0.35)$. Furthermore, respondents indicated their personal/social needs $($ Mean $=2.856$, Std. Dev. $=0.36)$ and practical needs $($ Mean $=2.838$, Std. Dev. $=$ 0.22 ). Base on the cut-off point, it can be said that the most important needs of the students were personal/social needs, practical needs, educational/academic and vocational needs. However, the topmost needs were personal/social and practical needs.

The study further examined the effect of gender on the counselling needs of students. The results are presented in Table 2. The results show that there was a significant difference in the counselling needs of male (Mean $=2.795$, Std. Dev. $=0.259)$ and female $($ Mean $=2.749$, Std. Dev. $=0.465)$ diploma students of the 
Table 1. Prevalent broad categories of counselling needs of students.

\begin{tabular}{ccc}
\hline Broad Counselling Needs of Students & Mean & Std. Dev. \\
\hline Educational/academic needs & 2.773 & 0.37 \\
Career/vocational needs & 2.772 & 0.35 \\
Personal/social needs & 2.856 & 0.36 \\
Practical needs & 2.838 & 0.23 \\
\hline
\end{tabular}

Source: Field survey (2019); where Std. Dev. = Standard Deviation $(\mathrm{N}=1075)$.

Table 2. Gender differences in broad categories of the students' counselling needs.

\begin{tabular}{cccccccc}
\hline Broad Categories of Needs & Gender & $\mathrm{N}$ & Mean & Std. Dev. & t-value & p-value & $\eta^{2}$ \\
\hline $\begin{array}{c}\text { Educational/academic } \\
\text { needs }\end{array}$ & Male & 553 & 2.795 & 0.259 & $2.005^{\star}$ & 0.044 & 0.004 \\
& Female & 522 & 2.749 & 0.465 & & & \\
Career/vocational needs & Male & 553 & 2.763 & 0.342 & -0.837 & 0.403 \\
& Female & 522 & 2.781 & 0.367 & & \\
\hline \multirow{2}{*}{$\begin{array}{c}\text { Personal/social needs } \\
\text { Mractical needs }\end{array}$} & Female & 522 & 2.869 & 0.377 & & \\
\hline \multirow{2}{*}{$\begin{array}{c}\text { Counselling needs of } \\
\text { students }\end{array}$} & Male & 553 & 2.848 & 0.220 & 1.427 & 0.154 \\
\hline & Female & 522 & 2.828 & 0.229 & & \\
\hline
\end{tabular}

Source: Field survey (2019). ${ }^{\star} \mathrm{p}<0.05, \mathrm{df}=1073$, where $\eta^{2}=$ Eta Square $(\mathrm{N}=1075)$.

College $[t=2.005, \mathrm{df}=1073, \mathrm{p}=0.044]$. The magnitude of the gender difference with respect to their educational/academic needs was small (eta square $\left(\eta^{2}\right)=$ 0.004). This shows that 0.4 percent of the variances in the students' counselling needs could be explained by their gender.

However, in relation to career/vocational $(\mathrm{t}=-0.837, \mathrm{df}=1073, \mathrm{p}=0.403)$, personal/social $(\mathrm{t}=-1.222, \mathrm{df}=1073, \mathrm{p}=0.222)$, and practical $(\mathrm{t}=1.427, \mathrm{df}=$ $1073, \mathrm{p}=0.154)$ needs, there were no significant differences between the male and the female students of the College. Overall, the results show that gender has no significant influence on the students' counselling needs $(t=0.324, \mathrm{df}=1073$, $\mathrm{p}=0.746)$.

The study further examined the influence of identifying priority counselling needs of students on students' academic success, taking into consideration the moderating role of organisational culture of the college and the effectiveness of the counselling service delivered by the counselling unit. Also, age and level of students were considered as controls. The results are presented in Table 3. The multiple regression analysis involved testing of three models. In the first model, the four priority needs of students were entered as independent variables. As depicted in Table 3, identifying all the four counselling needs of students contributed 37.2 percent significantly to their success $\left(R^{2}=0.372\right)$. Identifying personal-social $(\beta=0.231, \mathrm{p}<0.01)$ and practical $(\beta=0.220, \mathrm{p}<0.01)$ needs of 
Table 3. Incremental influence of identifying and meeting the counselling needs of students on their academic success.

\begin{tabular}{|c|c|c|c|c|c|c|c|c|c|c|c|c|c|c|c|}
\hline \multirow{3}{*}{ Variables } & \multicolumn{5}{|c|}{ Module I } & \multicolumn{5}{|c|}{ Module II } & \multicolumn{5}{|c|}{ Module III } \\
\hline & \multirow{2}{*}{$\begin{array}{l}\text { Std. Co. } \\
\text { Beta }(\beta)\end{array}$} & \multirow{2}{*}{$\mathrm{t}$} & \multirow{2}{*}{ Sig. } & \multicolumn{2}{|c|}{ Col. Stat. } & \multirow{2}{*}{$\begin{array}{l}\text { Std. Co. } \\
\text { Beta }(\beta)\end{array}$} & \multirow{2}{*}{$\mathrm{t}$} & \multirow{2}{*}{ Sig. } & \multicolumn{2}{|c|}{ Col. Stat. } & \multirow{2}{*}{$\begin{array}{l}\text { Std. Co. } \\
\text { Beta }(\beta)\end{array}$} & \multirow{2}{*}{$\mathrm{t}$} & \multirow{2}{*}{ Sig. } & \multicolumn{2}{|c|}{ Col. Stat. } \\
\hline & & & & Tol. & VIF & & & & Tol. & VIF & & & & Tol. & VIF \\
\hline Personal-social needs & $0.231^{\star *}$ & 3.848 & 0.000 & 0.358 & 2.347 & 0.004 & 0.167 & 0.867 & 0.940 & 1.064 & 0.006 & 0.276 & 0.783 & 0.936 & 1.068 \\
\hline $\begin{array}{c}\text { Educational/academic } \\
\text { needs }\end{array}$ & $0.148^{\star *}$ & 4.397 & 0.000 & 0.503 & 1.990 & $0.079^{*}$ & 2.582 & 0.013 & 0.600 & 1.668 & 0.029 & 1.050 & 0.294 & 0.585 & 1.710 \\
\hline Practical needs & $0.220^{\star *}$ & 7.689 & 0.000 & 0.694 & 1.440 & $0.107^{\star \star}$ & 4.148 & 0.000 & 0.847 & 1.180 & $0.114^{\star \star}$ & 4.915 & 0.000 & 0.846 & 1.182 \\
\hline $\begin{array}{c}\text { Career/vocational } \\
\text { needs }\end{array}$ & $0.112^{\star *}$ & 2.845 & 0.005 & 0.367 & 2.726 & $0.209^{* *}$ & 7.654 & 0.000 & 0.759 & 1.318 & $0.090^{\star *}$ & 3.400 & 0.001 & 0.649 & 1.541 \\
\hline Age of respondents & & & & & & $0.085^{* *}$ & 2.753 & 0.006 & 0.597 & 1.674 & $0.059^{*}$ & 2.116 & 0.035 & 0.587 & 1.704 \\
\hline Level of respondents & & & & & & $0.105^{\star}$ & 2.598 & 0.012 & 0.350 & 2.856 & $0.096^{\star *}$ & 2.630 & 0.009 & 0.343 & 2.915 \\
\hline $\begin{array}{l}\text { Organisational culture } \\
\text { of the college }\end{array}$ & & & & & & & & & & & $0.255^{\star *}$ & 9.290 & 0.000 & 0.601 & 1.663 \\
\hline $\begin{array}{l}\text { Effective counselling } \\
\text { service delivery }\end{array}$ & & & & & & & & & & & $0.129^{\star *}$ & 4.426 & 0.000 & 0.534 & 1.874 \\
\hline Constant & 1.132 & & & & & 0.844 & & & & & 0.636 & & & & \\
\hline $\mathrm{R}$ & 0.557 & & & & & 0.757 & & & & & 0.813 & & & & \\
\hline R Square $\left(\mathrm{R}^{2}\right)$ & 0.372 & & & & & 0.674 & & & & & 0.761 & & & & \\
\hline Adjusted R Square & 0.365 & & & & & 0.665 & & & & & 0.753 & & & & \\
\hline
\end{tabular}

Source: Field survey (2019), where Std. Co. $=$ Standardized Coefficients, Col. Stat. = Collinearity Statistics, Tol. $=$ Tolerance $(\mathrm{N}=1075) .{ }^{*}$ Correlation is significant at the 0.01 level (2-tailed). ${ }^{*}$ Correlation is significant at the 0.05 level (2-tailed). Dependent Variable: Perceived Academic Success.

students contributed more to students' academic success than identifying educational/academic $(\beta=0.148, \mathrm{p}<0.01)$ and career/vocational needs.

In the second model as indicated in Table 3, students' personal characteristics such as age and level of programme were entered into the model to serve as controls and to examine their influence. The two variables entered in the second module were all significant contributors to students' academic success. However, personal-social needs of students became non-significant. The total contribution increased from 37.2 percent to 47.4 percent. The rate of increase with regard to the $\mathrm{R}$ square $\left(\mathrm{R}^{2}\right)$ was 27.4 percent. That is, personal characteristics of students can influence their counselling needs.

In the third model, the two moderating variables: organisational culture of the college and the effectiveness of the counselling service delivery of the college, were entered into the second model to serve as moderating factors. The assumption of the study is that the independent variables do not strongly predict academic success of students, and that they do so indirectly when other factors are considered. As depicted in Table 3, organisational culture of the college contributed 25.5 percent while effective counselling delivery of the college contributed 12.9 percent when they were added into the module. This finding reinforces the argument that when the organisational culture of an institution does not support guidance and counselling activities, it indirectly influences students' success in academics. 
However, personal-social and educational/academic need became non-significant. The total contribution $\left(\mathrm{R}^{2}\right)$ of the variables when the two moderating variables were considered increased from 0.474 to 0.761 . This shows that when the moderating variables entered the model, the rate of increase of the $R^{2}$ was 60.5 percent. The findings mean that identifying the counselling needs of students, taking into consideration their personal characteristics will lead to students' academic success. However, when the organisational culture of the institution and the effectiveness of the counselling service delivery of the institution are considered, students' academic success becomes more significant and high. This is so because the system is able to meet the needs of the students.

\section{Discussion of the Results}

With regard to the broad categories of students' needs, results showed that students had the need for all. This implies that diploma students of CoDE are faced with many problems that are burn out of many factors including lack of information, money, accommodation, and food. However, students indicated that they had the need for personal/social and practical issues more. The findings are consistent with that of Awabil [6] who saw practical and personal/social needs as of greater concern to students. Again, the findings are consistent with the report of Okyere [15] which indicated that practical needs were the most pressing concern of students. This may mean that students of the college abysmal performance are as a result of their personal/social and practical needs.

Also, the finding that personal/social needs are the most ranked needs required by the students support the assumption of Maslow's theory of needs which states that our most basic need is for physical survival. This will be the first thing that motivates our behaviour. Once that level is fulfilled the next level up is what motivates us, and so on [16]. The need to satisfy one's personal/social needs becomes stronger the longer the duration they are denied. This shows that the students must satisfy their personal/social deficit needs before progressing to meet higher level needs such as career/vocational and educational/academic needs. When deficit need has been satisfied it will go away. Activities will then become habitually directed towards meeting the next set of needs that are yet to be satisfied.

The overall finding that there is no significant difference between male and female students with regard to their needs are incongruent with that of Awabil [6] who found out that students differed significantly in their counselling needs on the basis of gender. Again, the finding is inconsistent with the submission of Kangai [8] who suggest that male and female students have different needs with respect to the counselling services provided during their distance study. This suggests that male and female diploma students of the college experience similar problems and needs. Also, the finding that age and academic level have significant influences on students' counselling needs mean that older students have higher counselling needs than younger students. Also, the longer a student stays in the College, the greater his/her counselling needs. The findings are consistent 
with that of Awabil [6] who found that there was no significant difference in the counselling needs of students on the basis of age. Also, with regards to support services, young students are likely to need general academic advisement whilst older students seem to need individualised counselling services since they may experience more personal problems as they try to balance their studies with work and family responsibilities [8].

Through effective counselling strategies, institutions can help students to meet and satisfy most of their needs. The results show that identifying the needs are good influencers of meeting students' needs, which are perceived not to be adequately met by the College which to some extent may affect their academic success negatively. The findings that identifying and meeting the priority counselling needs of students and demographic characteristics such as age and academic level have significant influence on students' academic success support the assertion of the Astin's theory of I-E-O model. The findings helped in explaining and understanding the interdependence between the students and the College environment with regard to the counselling services put in place by the College and students' academic success.

Using the I-E-O model may mean that identifying the priority needs of students, taking into consideration the demographic characteristics of the students do exert influence on meeting the needs of the students which in turn influence the academic success of students. However, for academic success of the students to be strong and meaningful, the organisational culture of the college should be supportive, and also the counselling service delivery of the college should be effective. These dynamics will in turn boost academic success of the students significantly. This is in line with the assertion that isolating the environmental variables of interest of students in order to measure their educational impact will not be appropriate [16].

\section{Conclusions}

Based on the findings of the study, it can be concluded that respondents had four broad priority counselling needs. Also, with the exception of gender, all the personal characteristics of students (age and level of study) had significant influence on students' perception of their counselling needs. Furthermore, the counselling needs of distance students were not adequately met by the College. The study concludes that whenever the organisational culture of the college support the activities of the counselling unit, and also when the service delivery of the unit is perceived to be effective, the unit is able to meet students' identified priority needs. This phenomenon will translate into students' academic success. However, to enhance students' academic success meaningfully, students' personal characteristics such as gender, age and level of study should be considered when identifying and meeting the counselling needs of students. It is, therefore, necessary for the College and the University as a whole to nurture the kind of atmosphere such as providing both human and material resources. 
The priority counselling needs of students cannot be effectively addressed without resources. Human resource is the most valuable asset of any organisation in the delivery of its core mandate. It is the human resource component of any institution that makes all other structures and facilities work. To make the counselling service effective, the human resource component has to be strengthened. There should be counsellors at all the regional study centres. Quite apart from recruiting professional counsellors, training of course tutors to be paraprofessionals and the guidance and counselling course tutors who are professionals is required.

Material resources for effective service delivery, on the other hand, include office complex, equipment, finance, and time. There should be offices in the various study centres. The offices should be fully furnished to create a conducive environment for counselling. In the delivery of counselling services, confidentiality is of paramount importance. This can only be achieved when counselling is done indoors. There should be regular sources of funding for the running of the offices. Materials such as psychological tests and inventories, journals, leaflets, students' handbooks and stationeries should be made available. All these resources facilitate the effective delivery of counselling services.

That will support counselling activities and also lead to effective counselling service delivery in order to help boost the influence of identifying counselling needs on students' academic success by first meeting the identified counselling needs of the students.

\section{Conflicts of Interest}

The author declares no conflicts of interest regarding the publication of this paper.

\section{References}

[1] Somuah, B.A., Dankyi, L.A. and Dankyi, J.K. (2014) An Investigation into the Study Habits of Distance Learners: Implications for Guidance and Counselling Services. Mediterranean Journal of Social Sciences, 5, 273-282. https://doi.org/10.5901/mjss.2014.v5n6p273

[2] Akrofi, D. (2010) Distance Education at the University of Education, Winneba: Challenges and Prospects. Unpublished Master's Thesis, University of Cape Coast, Cape Coast.

[3] Jannatul-Firdaos, F. (2014) Student Perceptions as Distance Students in Internet-Based Courses: The Case of University of Ghana Students. Unpublished Master's Thesis, University of Ghana, Lagon.

[4] Agyemang, S.N. (2014) The Challenges Facing Distance Education Students at University of Ghana.

[5] Dunn, S.T.M. (2015) A Place of Transition: Directors' Experiences of Providing Counselling and Advising to Distance Students. Journal of Distance Education, 31, 40-57.

[6] Awabil, G. and Akande, E.A. (2013) Assessment of the Counselling Needs of Polytechnic Students in Nigeria: Implications for Resource Mobilisation. Ontario Journal of African Educational Research, 13, 37-56. 
[7] CoDE (2017) Profile of the College of Distance Education of University of Cape Coast Draft Report of Students' Academic Performance by Students' Records Unit, U. Report, University of Cape Coast, Cape Coast.

[8] Kangai, C., Rupande, G. and Rugonye, S. (2017) Students' Perceptions on the Quality and Effectiveness of Guidance and Counselling Services at the Zimbabwe Open University. An Online Journal of the African Educational Research Network, 18, 12-32.

[9] Carr, S. (2013) As Distance Education Comes of Age, the Challenge Is Keeping the Student. The Chronicle of Higher Education, 59, 39-41.

[10] CoDE (2018) Draft Report on Students' Graduation Rate. Unpublished Report, University of Cape Coast, Cape Coast.

[11] Appiah, E.K. (2013) Comparative Study of Guidance and Counselling at Kwame Nkrumah University of Science and Technology and Ashesi University College. Unpublished Master's Thesis, Kwame Nkrumah University of Science and Technology, Kumasi.

[12] Mishra, L.K. (2014) Academic Counselling in Distance Education: IGNOU Experience. Pedagogy of Learning, 2, 62-68.

[13] Mau, W.C. and Jepsen, D.A. (2017) Attitudes toward Counsellors and Counselling Processes: A Comparison of Chinese and American Distance Students. Journal of Counselling and Development, 96, 189-193. https://doi.org/10.1002/j.1556-6676.1988.tb02090.x

[14] Herr, E.L. (2017) The Impact of National Policies, Economics, and School Reform on Comprehensive Guidance Programmes. Professional School Counselling, 20, 236-246.

[15] Okyere, C.O., Awabil, G. and Nyarko-Sampson, E. (2015) Assessment of the Counselling Needs of Students in a Ghanaian Public University. Ghana Journal of Education: Issues and Practices, 1, 29-43.

[16] Hodge, K.N.F. (2015) Input and Environmental Variables Influencing Community College Student Satisfaction with Tech Prep Programmes in Texas. Unpublished Doctoral Dissertation, Texas Tech University, Lubbock.

[17] CoDE (2017) Draft Report on Students' Enrolment Statistics by Students' Records Unit. Unpublished Report, University of Cape Coast, Cape Coast.

[18] Kumar, R. (2014) Research Methodology: A Step-by-Step Guide for Beginners. 4th Edition, Sage, London.

[19] Apreko, A.A. (2010) Needs Assessment of Polytechnic Students in Ghana: The Case of Ho Polytechnic. Unpublished Master's Thesis, University of Cape Coast, Cape Coast.

[20] Yates, S.J. (2014) Doing Social Science Research. 2nd Edition, Sage Publications Ltd., London.

[21] Pallant, J. (2010) SPSS Survival Manual. McGraw-Hill, New York. 